\title{
AN OVERVIEW OF THE HEAT-AFFECTED ZONE SENSITIZATION AND STRESS CORROSION CRACKING BEHAVIOUR OF 12\% CHROMIUM TYPE 1.4003 FERRITIC STAINLESS STEEL
}

\author{
Du Toit M. ${ }^{*}$, Van Rooyen G.T. ${ }^{*}$ and Smith D. ${ }^{* *}$
}

\begin{abstract}
This document presents an overview of the findings of several investigations into the susceptibility of $12 \%$ chromium type 1.4003 ferritic stainless steel to heat-affected zone sensitization and intergranular stress corrosion cracking. A description of the sensitization behaviour of these steels is complicated by the partial transformation of $\delta$-ferrite to austenite on cooling. During slow cooling or annealing below the $A_{1}$ temperature, this austenite decomposes to form desensitized ferrite and $\mathrm{M}_{23} \mathrm{C}_{6}$-type carbide precipitates. The rapid cooling rates associated with welding, however, prevent the transformation of austenite to ferrite at lower temperatures, and any austenite formed on cooling transforms to martensite below the $\mathrm{M}_{\mathrm{s}}$-temperature. Four distinct modes of heat-affected zone sensitization have been identified to date. Sensitization of the martensite phase may occur on welding material inadvertently annealed above the $A_{1}$ temperature (Mode 1), or when multiple welds are positioned in such a way that the heat-affected zone of the $2^{\text {nd }}$ pass overlaps the heataffected zone of the $1^{\text {st }}$ pass (Mode 2). Rapid cooling after very low heat input welding may sensitize the ferrite phase (Mode 3), whereas very slow cooling after welding at excessively high heat input levels may lead to sensitization of the austenite phase (Mode 4). Results examining the influence of Modes 1 and 2 heat-affected zone sensitization on the incidence of intergranular stress corrosion cracking are presented.
\end{abstract}

\section{KEYWORDS}

Sensitization; stress corrosion cracking; stainless steel

\footnotetext{
AUTHOR DETAILS

* Department of Materials Science and Metallurgical Engineering, University of Pretoria, South Africa.

** Metallurgical Services, Columbus Stainless Pty (Ltd), South Africa.
} 


\section{INTRODUCTION}

Low-carbon, 11 to 12 per cent chromium ferritic stainless steels are widely used as low cost, utility stainless steels. These steels conform in composition to grades S41003 (ASTM A240) and 1.4003 (EN 10088-2 and EN 10028-7), with the specified chemical composition limits for these grades shown in Table 1. The EN 1.4003 type alloys perform well in many wet sliding abrasion applications and in aqueous environments, often replacing coated carbon and galvanized steels in mildly corrosive surroundings [1-3]. Initial application of these steels was confined to materials handling equipment in corrosive/abrasive environments, but the 1.4003 steels are now used extensively in the coal mining industry, for cane and beet sugar processing equipment, and for bulk transport of coal and ore.

Table 1 - Specified chemical composition limits for grades S41003 (ASTM A240) and 1.4003 (EN 10088-2 and EN 10028-7) (percentage by mass, balance Fe).

\begin{tabular}{|c|c|c|c|c|c|c|c|c|}
\hline Grade & $\mathbf{C}$ & $\mathbf{C r}$ & $\mathbf{M n}$ & $\mathbf{S i}$ & $\mathbf{N i}$ & $\mathbf{P}$ & $\mathbf{S}$ & $\mathbf{N}$ \\
\hline \multirow{2}{*}{$\mathrm{S} 41003$} & 0.030 & $10.5-$ & 1.50 & 1.00 & 1.50 & 0.040 & 0.030 & $\begin{array}{c}0.030 \\
\end{array}$ \\
& $\max$. & 12.5 & $\max$. & $\max$. & $\max$. & $\max$. & $\max$. & $\max$. \\
\hline \multirow{2}{*}{1.4003} & 0.030 & $10.5-$ & 1.50 & 1.00 & $0.30-$ & 0.040 & 0.015 & 0.030 \\
& $\max$. & 12.5 & $\max$. & $\max$. & 1.00 & $\max$. & $\max$. & $\max$. \\
\hline
\end{tabular}

The 1.4003 ferritic stainless steels are designed to transform partially to austenite on cooling, passing through the dual-phase (austenite+ferrite) phase field on the $\mathrm{Fe}-\mathrm{Cr}$ equilibrium phase diagram (shown in Figure 1 for carbon contents below 0.01 per cent). This partial solid-state phase transformation of ferrite to austenite on cooling improves the weldability and as-welded toughness of these steels by restricting heat-affected zone grain growth $[4,5]$. The 1.4003 steels are usually supplied in the fully annealed and desensitized condition. Final annealing is performed at temperatures below the $A_{1}$ (normally between $700^{\circ} \mathrm{C}$ and $750^{\circ} \mathrm{C}$ ) after air cooling or cold rolling [1,2]). During the annealing treatment, any austenite formed on slow cooling through the dual-phase region transforms completely to ferrite. Due to its low solubility in ferrite, the majority of the carbon precipitates as chromium-rich carbides or carbonitrides during annealing, but any chromium-depleted zones formed in the ferrite are healed through rapid chromium back-diffusion from the grain interiors.

The rapid cooling rates associated with welding, however, prevent the transformation of austenite to ferrite at lower temperatures, and any austenite formed on cooling through the dual-phase $(\delta+\gamma)$ region transforms to martensite below the $M_{s}$-temperature [4]. As a result of the high carbon solubility in austenite, the austenite phase that forms on cooling acts as a carbon sink, dissolving significant amounts of carbon. When this austenite transforms to martensite at lower temperatures, the amount of carbon retained in solid solution in the martensite phase is determined by the cooling rate. Martensite formed on fast cooling retains higher levels of the carbon in supersaturated solid solution. At slower cooling rates, the formation of martensite is preceded by carbide precipitation in the austenite, and less carbon is retained in solution in the martensite phase [6].

The typical heat-affected zone microstructure of a 1.4003 weld is shown in Figure 2. The high temperature heat-affected zone (HTHAZ) adjacent to the fusion line represents parent metal heated above the $A_{3}$ temperature during the weld thermal cycle, and is characterized by $\delta$-ferrite grains surrounded by grain boundary martensite. Despite the partial solid-state phase transformation from ferrite to austenite on cooling, the HTHAZ is normally characterized by a coarse grain size. This is in contrast to the much finer grain size of the low temperature heat-affected zone (LTHAZ) further removed from the fusion line. This region has a structure consisting of ferrite and martensite, and represents parent metal heated to temperatures between the $A_{1}$ and $A_{3}$ temperatures during welding.

Austenitic consumables are preferred for welding the 1.4003 alloys. Although this leads to a property mismatch between the weld and the surrounding base metal, the tough austenitic 
weld metal improves the overall toughness of the weld by absorbing some of the impact that the joint may be exposed to during service. A matching welding electrode is commercially available (classified as E410NiMo, with modified chromium content), but it is not recommended in applications where impact, shock, fatigue or any other form of non-static loading is anticipated. This electrode is only specified in applications where matching corrosion resistance is essential.

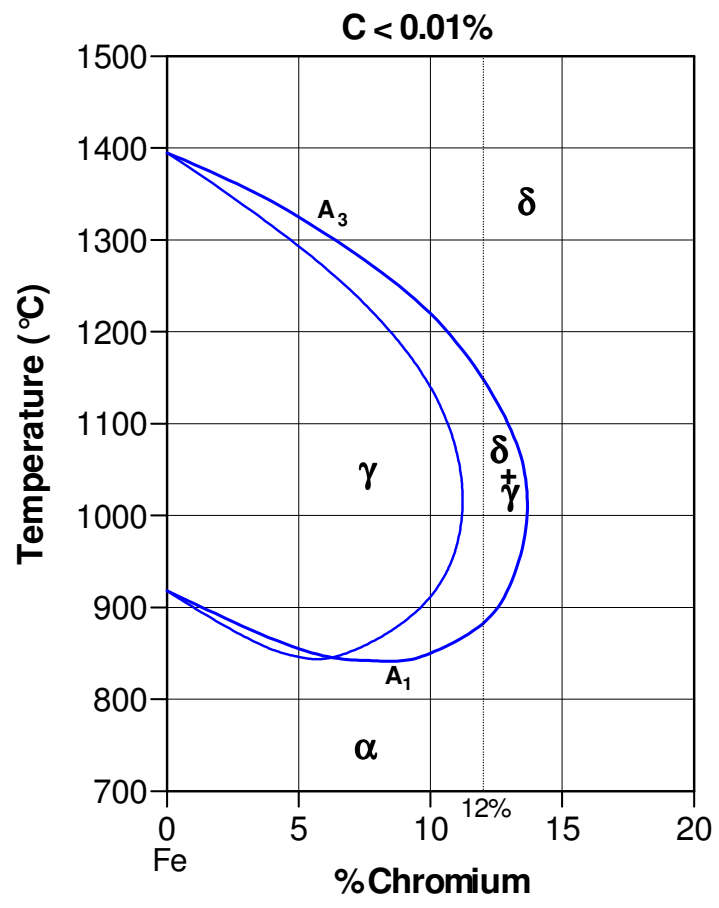

Figure 1 - Vertical section of the ternary Fe-Cr-C phase diagram at carbon contents below $0.01 \%$. Although the 1.4003 steels normally contain more than $0.01 \%$ carbon, this phase diagram illustrates the general shape of the austenite and (austenite+ferrite) phase fields. An increase in $\mathrm{C}$ content is expected to enlarge these phase fields at the expense of ferrite [7].

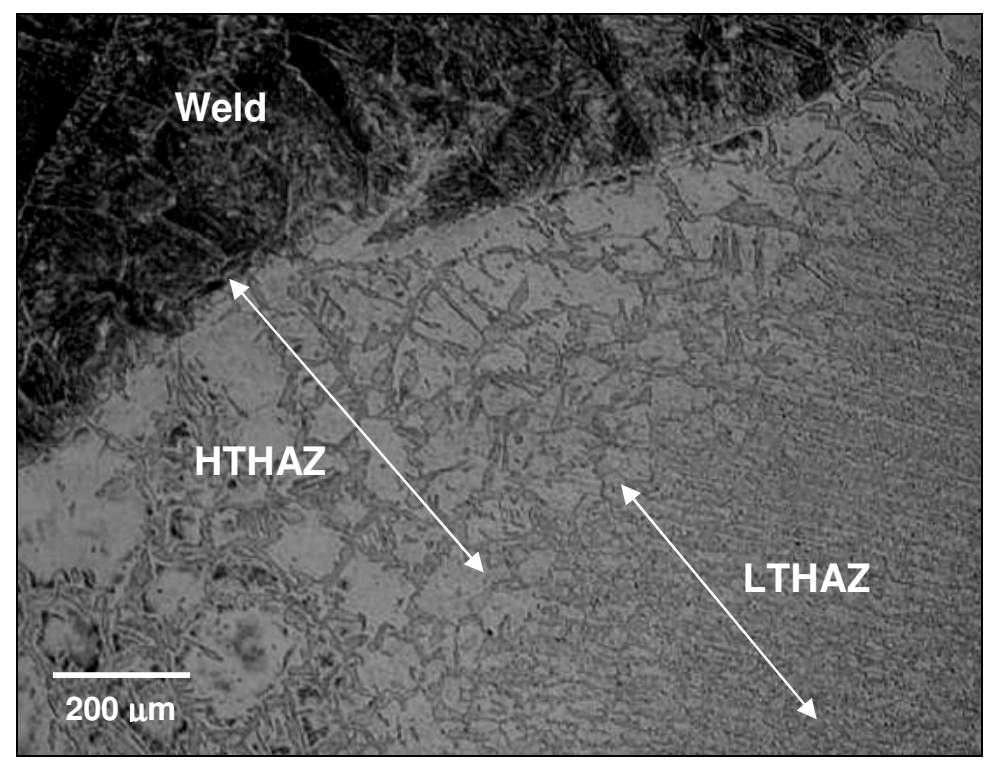

Figure 2 - The typical heat-affected zone microstructure of a type 1.4003 steel. (Welded at a heat input of $0,9 \mathrm{~kJ} / \mathrm{mm}$ and electrolytically etched in a saturated oxalic acid solution) [8]. 


\section{SENSITIZATION IN THE HEAT-AFFECTED ZONE OF 1.4003 WELDS}

A number of field failures of 1.4003 welds due to intergranular stress corrosion cracking and pitting corrosion in the heat-affected zone have been reported in the past decade [6]. Although it is frequently claimed that nickel-free stainless steels are immune to stress corrosion cracking, such failures have been reported in both nickel-free ferritic and martensitic stainless steels with corrosion potentials within the passive range [9-11]. The stress corrosion cracking of these stainless steels is generally believed to be associated with some degree of sensitization. Even though various sensitization models have been proposed for stainless steels, chromium depletion is the most widely accepted mechanism [12]. This theory states that sensitization is caused by intergranular precipitation of chromium-rich $\mathrm{M}_{23} \mathrm{C}_{6}$-type carbides, resulting in chromium depletion of the matrix surrounding the precipitated particles. If chromium depletion reduces the chromium level in the affected areas to below the concentration required to maintain passivation, the steel becomes sensitized to intergranular corrosion.

It was originally believed that the typical dual-phase heat-affected zone microstructure that develops during welding (as shown in Figure 2) renders the 1.4003 type steels largely immune to sensitization. The cooling rates during welding are generally considered to be too fast to cause sensitization of the austenite phase, whereas the ferrite phase is rapidly desensitized by chromium back-diffusion into depleted regions during cooling. This mechanism is similar to that proposed for the enhanced sensitization resistance observed in duplex austenitic-ferritic stainless steels [13]. It has, however, since been confirmed that the 1.4003 steels are susceptible to sensitization under specific conditions.

The chromium depletion mechanism for sensitization in the 1.4003 steels has been confirmed using transmission electron microscopy with electron energy loss (EELS) image filtering. Sensitized material demonstrates chromium enrichment along the grain boundaries, as well as distinctive chromium depleted zones adjacent to these boundaries [14]. The intergranular precipitation of chromium-rich carbides with associated grain boundary chromium depletion in dual-phase ferritic-martensitic 12 and $13 \%$ chromium steels has also been reported by Tomari et al [15] and Frangini et al [16].

Investigation into the phenomenon of heat-affected zone sensitization revealed that it only occurs under very specific conditions in the 1.4003 steels. Although these conditions are readily simulated in the laboratory, actual instances of failure in service have been rare. Laboratory simulations and in-service inspection of welds revealed four potential categories or modes of heat-affected zone sensitization in these materials. A brief description of each of the four modes is given below.

\subsection{Mode 1: Sensitization caused by welding incorrectly annealed material}

The initial in-service failures of unstabilized 1.4003 welds, now identified as Mode 1 failures, occurred in an industrial marine atmosphere and were characterised by intergranular pitting and stress corrosion cracking in the heat-affected zone of welds located within base metal with a dual-phase ferrite-martensite microstructure [17]. Mode 1 heat-affected zone failures are normally characterised by pitting corrosion and intergranular cracking within the LTHAZ, a short distance (typically a few millimetres) from the weld toe (as shown in Figure 3). Corrosive attack initially manifests as intergranular pitting corrosion, but in the presence of sufficiently high operating and residual stresses, may develop into intergranular stress corrosion cracking (IGSCC). Mode 1 failures are strongly linked to heat-affected zone sensitization, and the presence of chromium-rich grain boundary carbides has been verified in heat-affected zones that exhibit IGSCC.

The majority of heat-affected zone failures associated with intergranular stress corrosion cracking and sensitization in the 1.4003 steels is caused by the application of a double heating cycle. The first step involves heating the steel to a temperature within the $(\gamma+\delta)$ phase field above the $A_{1}$ temperature. The actual $A_{1}$ temperature is a function of the steel 
composition, and in steels with relatively high $A_{1}$ temperatures (above about $800^{\circ} \mathrm{C}$ ), partial dissolution of carbides can occur within the ferrite during this heating step. Due to the low carbon solubility in ferrite, any carbon liberated through the dissolution of carbide precipitates is absorbed preferentially by the austenite phase. If the steel is cooled sufficiently fast, the austenite transforms to unsensitized martensite with a high level of carbon in supersaturated solid solution. If this martensite is subsequently heated to a temperature within the carbide precipitation range of approximately $550^{\circ} \mathrm{C}$ to $850^{\circ} \mathrm{C}$ (the second step in the thermal cycle), sensitization of the martensite phase may occur. Most Mode 1 failures appear to be located within the portion of the heat-affected zone heated to temperatures between about $650^{\circ} \mathrm{C}$ to $700^{\circ} \mathrm{C}$, the temperature range that has been shown to produce the maximum degree of sensitization in laboratory simulation tests $[6,17]$.

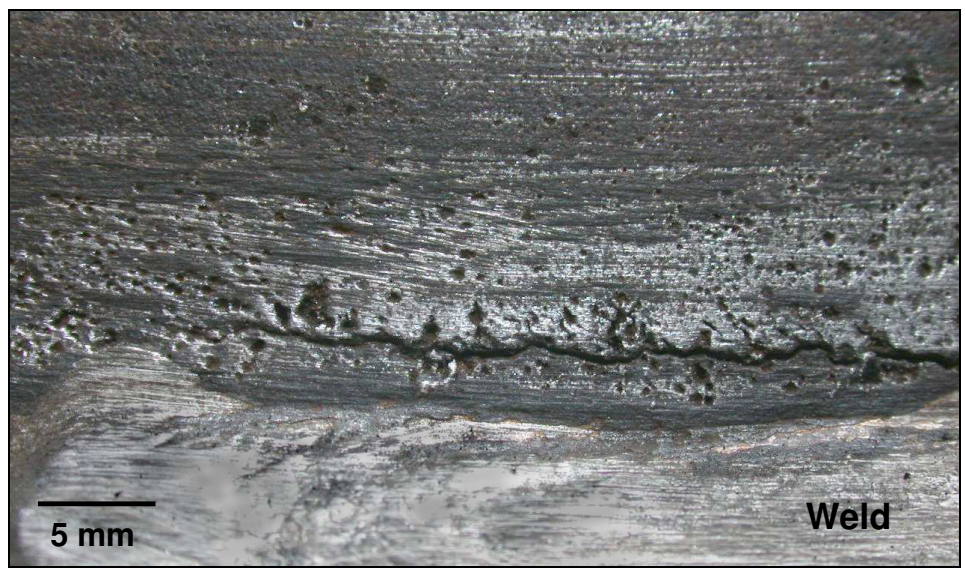

Figure 3 - Mode 1 pitting and intergranular cracking within the heat-affected zone of a weld deposited on incorrectly annealed base metal.

The susceptibility of 1.4003 steels to Mode 1 heat-affected zone sensitization is determined by the base metal microstructure prior to welding, and these failures are only observed on welding parent material with a dual-phase ferrite-martensite microstructure. The formation of unsensitized martensite within the base metal requires the steel to be heated above the $A_{1}$ temperature, followed by sufficiently fast cooling to prevent the transformation of austenite to ferrite. In the case of Mode 1 failures, this heating step normally occurs during the processing of the material. Significant amounts of unsensitized martensite has been reported at the ends or edges of coils after hot strip rolling [17]. These peripheral coil regions cool faster than the remainder of the coil, unless special measures are taken during coil cooling to reduce the cooling rate. Martensite may form in these regions if the cooling rate exceeds about $2^{\circ} \mathrm{C} /$ minute. The majority of Mode 1 failures observed in the field, however, occurred in base metal inadvertently heated above the $A_{1}$ temperature during continuous annealing after cold rolling. If annealing is incorrectly carried out above the $A_{1}$ temperature, followed by air cooling, untempered martensite can form. The amount of carbon dissolved in the martensite depends on the amount of austenite that formed above the $A_{1}$ temperature. The lower the percentage austenite, the higher the carbon content of the resultant martensite, rendering it highly susceptible to sensitization during subsequent welding operations. Mode 1 sensitized heat-affected zones may be susceptible to intergranular attack in relatively weak solutions due to the high carbon content of the sensitized martensite [6].

Mode 1 failures cannot be corrected by weld repair since the heat-affected zones of any subsequent repair welds will most likely be situated in base metal containing untempered martensite, thereby creating new sensitized zones within the metal. Mode 1 sensitization in unstabilized grades of 1.4003 can be prevented by ensuring that final annealing is always performed below the $A_{1}$ temperature of the alloy. Titanium-stabilized 1.4003 grades are not susceptible to this type of failure. 


\subsection{Mode 2: Sensitization of welds with overlapping heat-affected zones}

Mode 2 sensitization has a similar metallurgical mechanism to that described for Mode 1 failures, and also requires the application of a double heating cycle. The main difference between Modes 1 and 2 is that the conditions required for Mode 1 sensitization are produced as a result of incorrect processing (such continuous annealing above the $A_{1}$ temperature), whereas Mode 2 develops as a result of "overlapping" heat-affected zones formed on deposition of multiple welding passes. The base metal microstructure and prior heat treatment condition of the steel are therefore not relevant in the case of Mode 2 failures. The occurrence of Mode 2 sensitization depends on several factors, including the weld configuration, the weld sequence and the joint geometry. Failures have been observed in isolated cases at double fillet welds, double butt welds, repair welds, weld stop/start positions and tack welds [6].

During the first weld, untempered martensite can form in any part of the heat-affected zone heated above the $A_{1}$ temperature. Since the cooling rate after welding is normally fast and the $\mathrm{M}_{\mathrm{s}}$-temperature well below the temperature range where carbide precipitation occurs, this martensite remains unsensitized on cooling, but usually contains a high level of carbon in supersaturated solid solution. For sensitization to occur, the martensite needs to be reheated to a temperature within the carbide precipitation range. A second weld, positioned in such a way that the $550^{\circ} \mathrm{C}$ to $650^{\circ} \mathrm{C}$ temperature range coincides with the $\mathrm{HTHAZ}$ or LTHAZ of the first weld, may lead to the precipitation of chromium-rich carbides and sensitization of the martensite phase if insufficient time is available for chromium backdiffusion into any depleted zones. On exposure to a corrosive environment, the sensitized martensite phase is attacked preferentially, as shown in Figure 4.

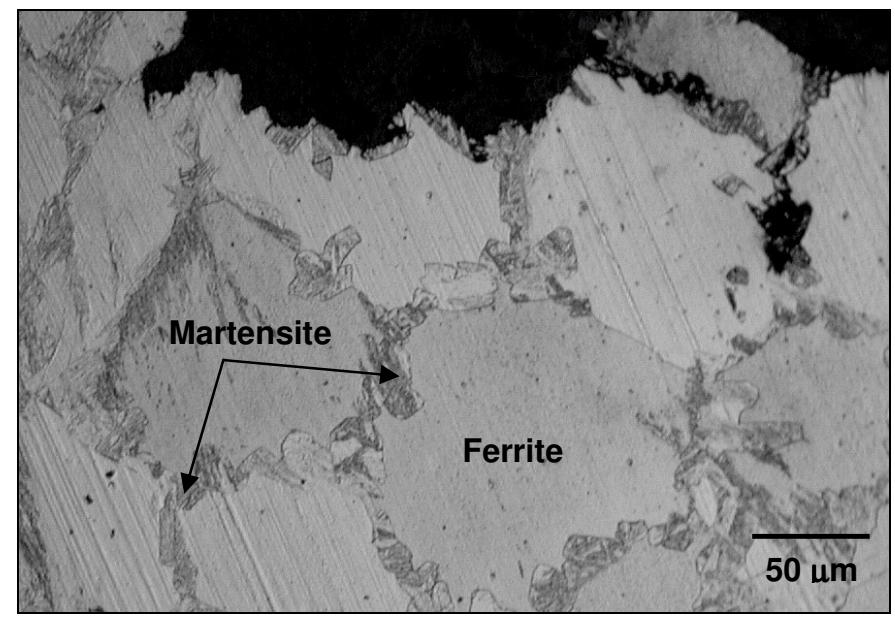

Figure 4 - Preferential attack of the sensitized martensite phase in the HTHAZ of an overlay weld.

Although Mode 2 sensitization is readily simulated under laboratory conditions, very specific positioning of welds is required for it to occur in practice. Parallel welds distanced in such a way that their heat-affected zones overlap, or intersecting welds may be affected, as illustrated schematically in Table 2. Excessive heat input levels during welding may promote failure by widening the heat-affected zone. Potential overlap then becomes more likely. Higher heat input levels also lead to longer residence times above the $A_{1}$ temperature during welding, resulting in more extensive carbide dissolution and higher levels of carbon in the martensite phase [6].

Mode 2 sensitization can be prevented by avoiding weld configurations and joint geometries that produce overlapping heat-affected zones. Titanium-stabilized grades of 1.4003 are not susceptible to Mode 2 sensitization. 
Table 2 - Schematic illustration of double welds, with potentially sensitized regions highlighted in black.

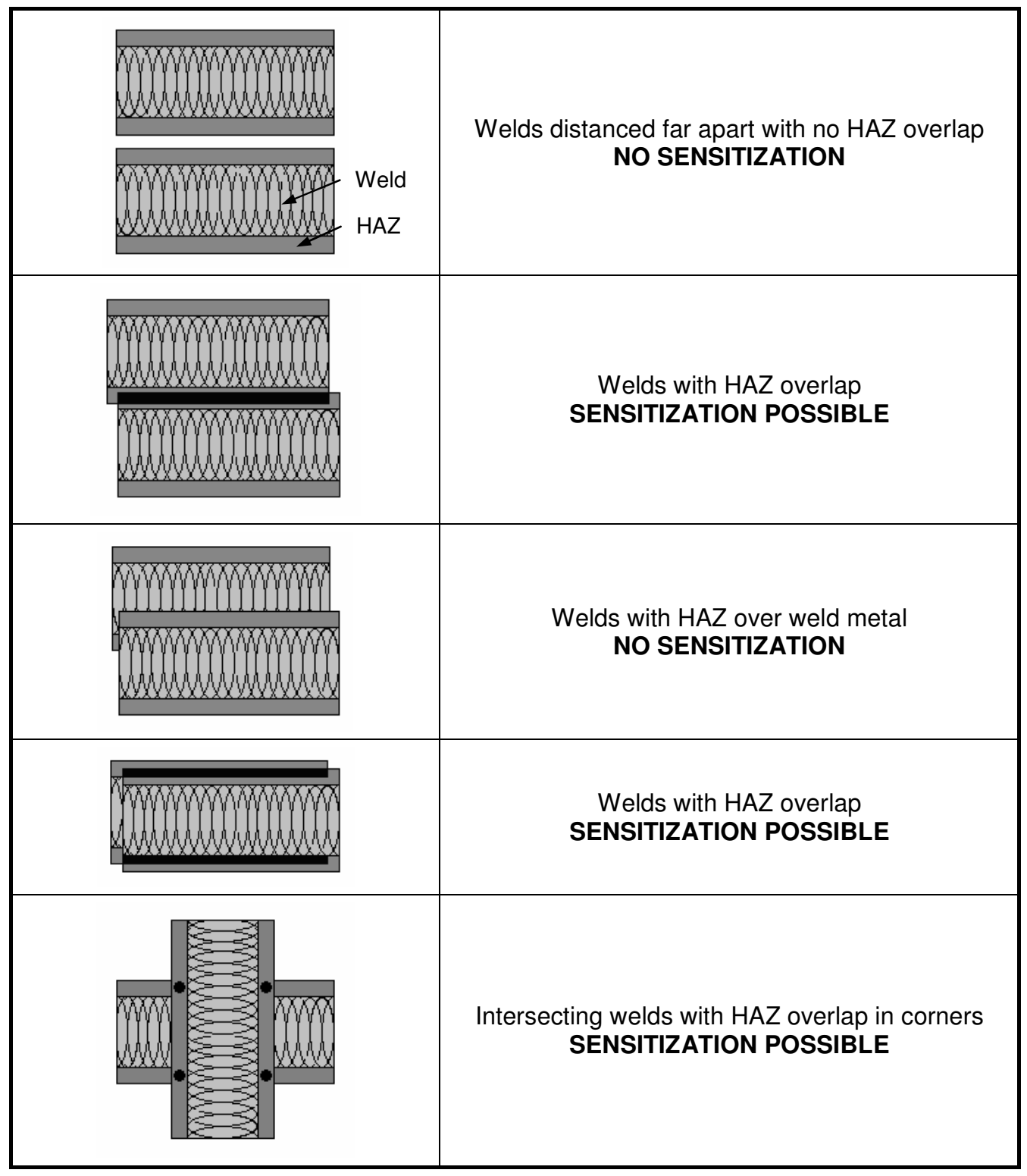

\subsection{Mode 3: Sensitization during continuous cooling after welding at low heat input} levels

A number of fillet weld failures attributed to IGSCC and sensitization suggested that sensitization can also occur during continuous cooling after welding, without recourse to the double heating cycle described above. These failures were associated with fast welding speeds and excessive fillet weld overlap, implying that low heat inputs play a role in promoting sensitization under these conditions. A similar mode of attack has been observed in areas associated with arc strikes, shallow rapidly solidified weld toe cusp features caused by welder hand movements in manual welding, and certain spatter features [17]. Mode 3 sensitization only occurs in the high temperature heat-affected zone and is unrelated to the parent metal microstructure. Sensitization occurs in the vicinity of the weld toe where the maximum joint stress concentration may be expected, and as a result intergranular defects caused by Mode 3 sensitization have been observed to initiate and accelerate fatigue cracking in highly stressed locations [17]. 
Mode 3 sensitisation occurs when low heat input welding results in very fast cooling rates during the early stages of the weld thermal cycle. These rapid cooling rates can suppress austenite nucleation as the heat-affected zone cools through the dual-phase (austenite+ferrite) phase field, resulting in almost fully ferritic high temperature heat-affected zone microstructures. Due to the low solubility of carbon in ferrite, the ferrite phase becomes supersaturated in carbon in the absence of sufficient austenite, and extensive carbide precipitation occurs at the ferrite-ferrite grain boundaries during cooling. The fast cooling rates also prevent the back-diffusion of chromium to the depleted regions adjacent to the chromium-rich carbides, resulting in a continuous network of sensitized ferrite-ferrite grain boundaries (as shown in Figure 5) [18].

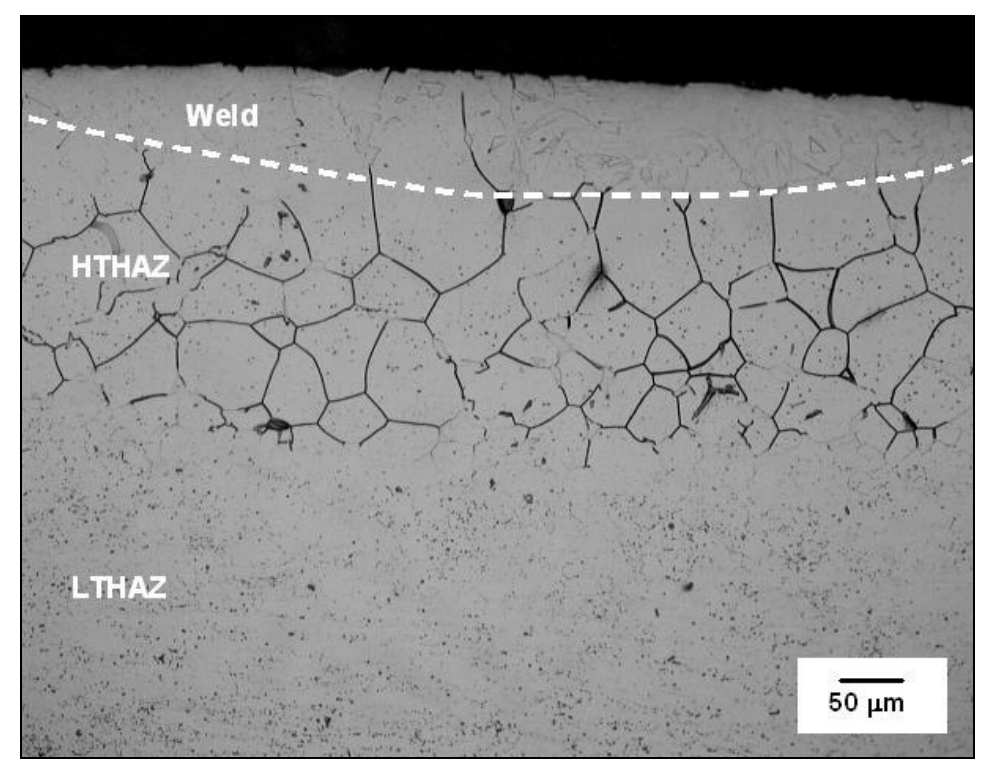

Figure 5 - Optical photomicrograph of an autogenous bead-on-plate weld welded at a heat input of $0.03 \mathrm{~kJ} / \mathrm{mm}$ (etched electrolytically in 10 per cent oxalic acid). A continuous network of ditched ferrite-ferrite grain boundaries is visible in the HTHAZ [18].

The degree of sensitization under low heat input conditions is a function of the metallurgical phase balance in the HTHAZ, and decreases significantly with an increased volume fraction of austenite on cooling. If enough austenite forms to absorb excess carbon (austenite has a higher carbon solubility than ferrite), a continuous network of chromium-depleted zones does not form and sensitization is prevented. The HTHAZ phase balance is determined largely by the cooling rate after welding and by the steel composition. As the heat input during welding increases, the cooling rate is reduced and more austenite forms in the heat-affected zone (as shown in Figure 6). This austenite transforms to martensite at lower temperatures and is retained down to room temperature as a grain boundary martensite network within the ferritic heat-affected zone. Slower cooling after welding at higher heat input levels also allows the ferrite to desensitize through diffusion of chromium from the grain interiors into any chromium depleted zones [18].

The chemical composition of the steel affects the HTHAZ phase balance by influencing the temperature range over which austenite is stable on cooling. The amount of ferrite retained in the HTHAZ can be estimated from the empirical Kaltenhauser ferrite factor (KFF), shown in equation (1) [19]. In low KFF steels, the austenite stability range extends to higher temperatures and over a wider temperature range than in high KFF steels. As illustrated in Figure 6, this favours the ferrite-to-austenite transformation, even under rapid cooling conditions, resulting in higher martensite levels in the HTHAZ after cooling.

$$
\mathrm{KFF}=[\mathrm{Cr}+6 \mathrm{Si}+8 \mathrm{Ti}+4 \mathrm{Mo}+2 \mathrm{Al}+4 \mathrm{Nb}]-[2 \mathrm{Mn}+4 \mathrm{Ni}+40(\mathrm{C}+\mathrm{N})]
$$




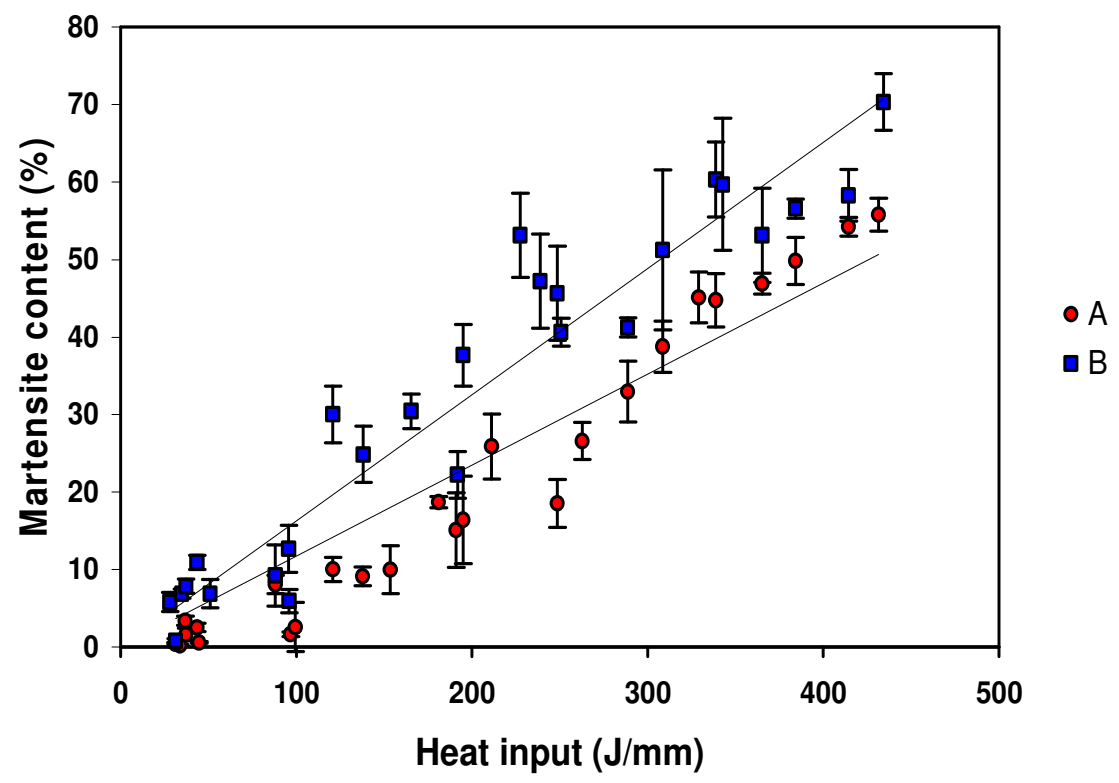

Figure 6 - The amount of martensite measured in the HTHAZ of two 1.4003 steels as a function of heat input during welding. Steel A has a KFF of 12.05; and steel B a KFF of 9.59 [18].

Mode 3 sensitization can be prevented by ensuring that heat input levels during welding do not fall below about $0.5 \mathrm{~kJ} / \mathrm{mm}$, and by using steels with high austenite potentials (i.e. low KFF steels) to promote the formation of austenite on cooling. Titanium-stabilized steels with high ferrite factors may be susceptible to Mode 3 sensitization, since titanium carbide or carbonitride precipitates are known to dissolve to varying degrees during the weld thermal cycle [17]. The reprecipitation of these particles may be prevented by the fast cooling rates experienced during the initial stages of cooling after welding. As shown in Figure 7, the cooling rate is reduced at lower temperatures, which may allow grain boundary $\mathrm{M}_{23} \mathrm{C}_{6}$ precipitation and sensitization to occur.

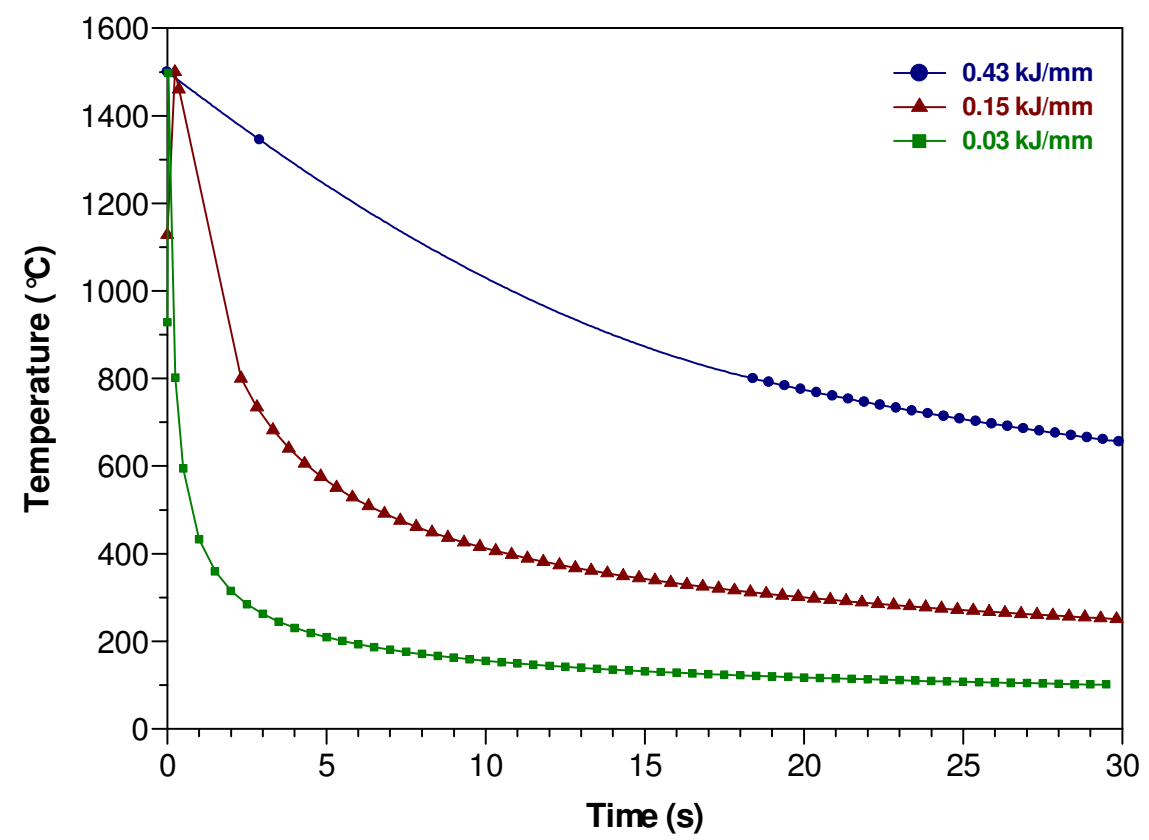

Figure 7 - Calculated temperature-time profiles experienced by a point located on the fusion line for three heat input levels and a plate thickness of $3 \mathrm{~mm}[18]$. 


\subsection{Mode 4: Sensitization on welding at excessively high heat input levels}

Cooling rates associated with arc welding are usually fast enough to prevent sensitization of any austenite formed on cooling through the dual-phase $(\delta+\gamma)$ region. Sensitization of austenite (designated as Mode 4 failure) may, however, occur in unstabilized grades of 1.4003 steel under very slow cooling conditions associated with welding at excessively high heat input levels. At elevated temperatures during cooling, the heat-affected zone of 1.4003 steels may be largely austenitic (depending on the alloy composition and austenite potential). This austenite is enriched in carbon and if the cooling rate is sufficiently slow, may sensitize on cooling. The intergranular SCC fracture surface of a Mode 4 sensitized specimen is shown in Figure 8.

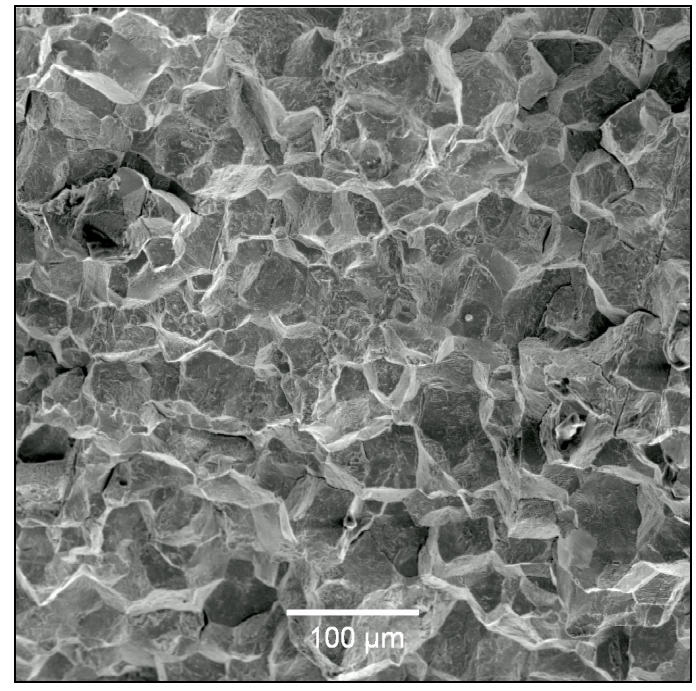

Figure 8 - Scanning electron micrograph of the intergranular SCC fracture surface of a Mode 4 sensitized sample. Cracking occurred along the sensitized prior austenite grain boundaries. (Unpublished research).

Mode 4 sensitization is the least common of the four modes of heat-affected zone sensitization in the 1.4003 steels. It is normally found within a very narrow band (generally less than $100 \mu \mathrm{m}$ wide) at the border between the HTHAZ and the LTHAZ in the vicinity of the $A_{1}$ peak temperature isotherm. Sensitization is occasionally restricted to the body of the plate, with the plate surface remaining largely unaffected. The occurrence of sensitization within such a narrow band suggests that very specific conditions have to be met for Mode 4 sensitization to occur.

The incidence of Mode 4 sensitization is dependent, not only on the cooling rate, but also on the kinetics of the decomposition of austenite below the $A_{1}$ temperature. This decomposition of austenite into ferrite and carbide phases occurs spontaneously below the $A_{1}$ temperature, provided enough time is available for nucleation and growth. In Figure 9, this transformation is schematically illustrated as the crosshatched region at higher temperatures. If the timetemperature-sensitization curve of the austenite phase is located at shorter times than the decomposition of austenite (as illustrated in Figure 9(a)), Mode 4 sensitization may occur if the cooling curve is located between the limits shown for the sensitization of austenite in Figure 9(a). In practice, however, the precipitation of $\mathrm{M}_{23} \mathrm{C}_{6}$ carbides on the austenite grain boundaries may be interrupted by the transformation of austenite to ferrite. This situation is demonstrated schematically in Figure 9(b). Any ferrite formed as a result of the decomposition of austenite desensitizes rapidly through chromium back-diffusion, and the material does not sensitize. Some sensitization of austenite prior to its decomposition to ferrite therefore does not present a problem in most practical situations, and no field failures attributed to stress corrosion cracking as a result of Mode 4 sensitization have been encountered to date. 
Mode 4 sensitization can be prevented by ensuring that heat input levels during welding do not exceed approximately $1.5 \mathrm{~kJ} / \mathrm{mm}$. This is in line with standard practice during the welding of 1.4003 steels, which limits heat input levels to a maximum of $1 \mathrm{~kJ} / \mathrm{mm}$ to control heat-affected zone grain growth. During multiple-pass welding, interpass temperatures need to be restricted to a maximum of $150^{\circ} \mathrm{C}$ to control the rate of cooling after welding. Titaniumstabilized grades of 1.4003 are not susceptible to Mode 4 sensitization.

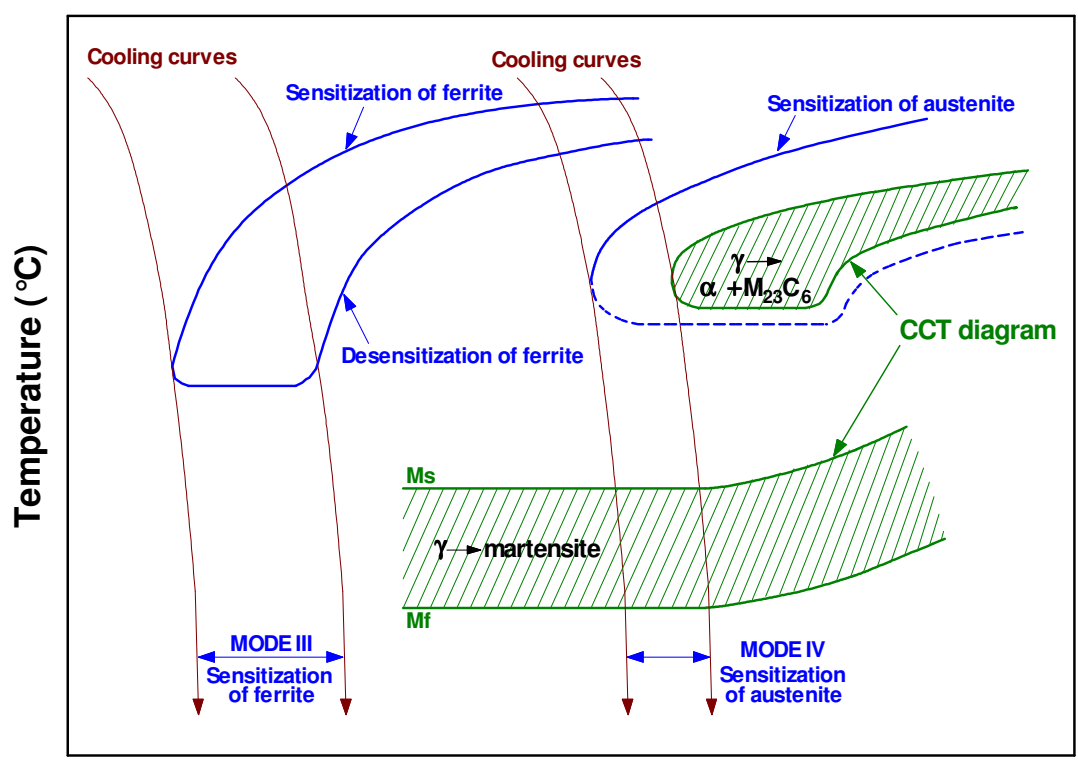

log time

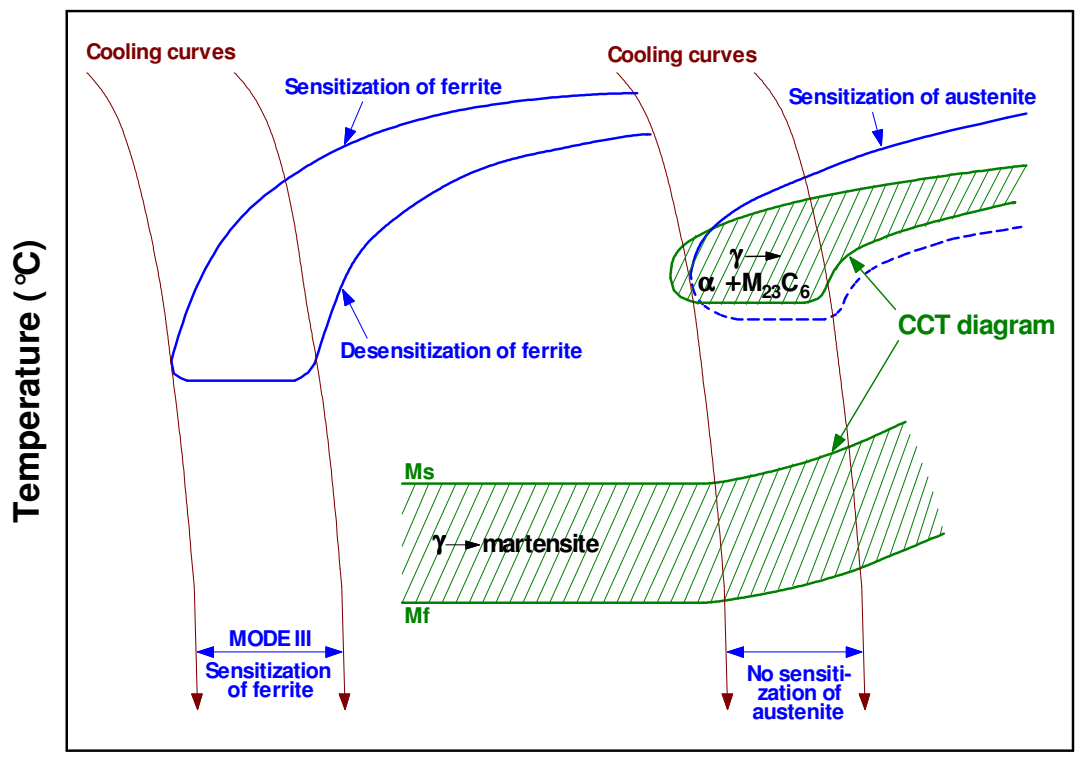

log time

Figure 9 - Schematic time-temperature-sensitization diagrams for 1.4003 steel illustrating the conditions leading to possible Mode 3 and Mode 4 sensitization during continuous cooling: (a) Mode 4 sensitization possible; and (b) Mode 4 sensitization unlikely as a result of the early decomposition of austenite into ferrite and carbide. 


\subsection{Summary of the four modes of heat-affected zone sensitization in 1.4003 steels}

A brief summary of the four possible modes of heat-affected zone sensitization in the 1.4003 steels is presented in Table 3.

Table 3 - Summary of the conditions leading to the four modes of heat-affected zone sensitization in 1.4003 steels.

\begin{tabular}{|c|l|l|l|}
\hline Mode & \multicolumn{1}{|c|}{ Imposed thermal cycle } & \multicolumn{1}{|c|}{$\begin{array}{c}\text { Relevant weld } \\
\text { processing conditions }\end{array}$} & Sensitized structure \\
\hline 1 & $\begin{array}{l}\text { Double thermal cycle, with heating } \\
\text { above the } \mathrm{A}_{1} \text { temperature during } \\
\text { final annealing, followed by a } \\
\text { second heating step to temperatures } \\
\text { between about } 650^{\circ} \mathrm{C} \text { and } 700^{\circ} \mathrm{C}\end{array}$ & $\begin{array}{l}\text { LTHAZ of a weld } \\
\text { deposited on base metal } \\
\text { containing untempered } \\
\text { martensite }\end{array}$ & $\begin{array}{l}\text { Martensite with Cr-rich } \\
\text { carbide precipitation on } \\
\text { the prior austenite grain } \\
\text { boundaries }\end{array}$ \\
\hline 2 & $\begin{array}{l}\text { Double thermal cycle, with heating } \\
\text { above the } \mathrm{A}_{1} \text { temperature, followed } \\
\text { by a second heating step to } \\
\text { temperatures between about } 550^{\circ} \mathrm{C} \\
\text { and } 650^{\circ} \mathrm{C}\end{array}$ & $\begin{array}{l}\text { Multiple welds positioned } \\
\text { in such a way that the } \\
\text { HAZ of the } 2^{\text {nd }} \text { pass } \\
\text { overlaps the HAZ of the } \\
1^{\text {st }} \text { pass }\end{array}$ & $\begin{array}{l}\text { Martensite with Cr-rich } \\
\text { carbide precipitation on } \\
\text { the prior austenite grain } \\
\text { boundaries }\end{array}$ \\
\hline 3 & $\begin{array}{l}\text { Heating to a temperature close to } \\
\text { the liquidus, followed by rapid } \\
\text { cooling }\end{array}$ & $\begin{array}{l}\text { HTHAZ generated by } \\
\text { single-pass low heat input } \\
\text { welds, arc strikes or } \\
\text { areas with excessive fillet } \\
\text { weld overlap }\end{array}$ & $\begin{array}{l}\text { Coarse-grained } \delta \text {-ferrite } \\
\text { with precipitation of Cr- } \\
\text { rich carbides at } \\
\text { continuous ferrite-ferrite } \\
\text { grain boundaries }\end{array}$ \\
\hline 4 & $\begin{array}{l}\text { Heating to a temperature close to } \\
\text { the liquidus, followed by very slow } \\
\text { cooling }\end{array}$ & $\begin{array}{l}\text { HTHAZ generated by } \\
\text { single-pass welds } \\
\text { performed at excessively } \\
\text { high heat input levels }\end{array}$ & $\begin{array}{l}\text { Carbide precipitation at } \\
\text { austenite grain } \\
\text { boundaries during } \\
\text { cooling }\end{array}$ \\
\hline
\end{tabular}

\section{STRESS CORROSION CRACKING}

The incidence of intergranular stress corrosion cracking within the heat-affected zone of 1.4003 welds is reported to be closely associated with heat-affected zone sensitization. To date, the majority of investigations has focused on the influence of Mode 1 or Mode 2 sensitization, i.e. sensitization of the martensite phase as a result of the application of a double thermal cycle, on the SCC of 1.4003 steels. Under these conditions, SCC failures are intergranular and cracking is confined to the martensite phase, in particular along the prior austenite grain boundaries. Under general corrosion conditions, the martensite phase corrodes preferentially. SCC of sensitized martensite can therefore be described as anodic dissolution of the prior austenite grain boundaries, assisted by the application of external stress. The results of a number of these investigations are considered below.

\subsection{U-bend testing}

Van Rooyen [20] studied the stress corrosion cracking susceptibility of unwelded 1.4003 steel by annealing $3 \mathrm{~mm}$ thick U-bend test specimens at $950^{\circ} \mathrm{C}$ for 10 minutes, followed by water quenching. This treatment simulated incorrect annealing practice and produced material consisting of coarse-grained $\delta$-ferrite surrounded by a layer of unsensitized grain boundary martensite. The U-bend samples were then tempered at various temperatures in order to sensitize the carbon supersaturated martensite, and stressed by means of a straingauged load cell that was designed to be twice as stiff as the test specimen. Cracking of the sample during testing therefore resulted in a decrease in stiffness and consequently a reduction in the applied load. By continuously recording the applied load, instantaneous detection of the advent of cracking and ongoing monitoring of crack propagation were facilitated. The stressed specimens were immersed in a $5 \%$ (by volume) $\mathrm{H}_{2} \mathrm{SO}_{4}$ solution in 
which the potential of the sample with respect to a saturated calomel electrode (SCE) could be controlled potentiostatically. Initially the specimen potential was controlled within the passive range $\left(0.5 \mathrm{~V}_{\mathrm{SCE}}\right)$, followed by very slow scanning towards the active region over a period of two days. Cracking of sensitized specimens only occurred when the corrosion potential was located at the boundary between the active and passive states within a narrow potential band ranging from $+0.25 \mathrm{~V}_{\mathrm{SCE}}$ to $0 \mathrm{~V}_{\mathrm{SCE}}$. Cracking could be interrupted by reversing the potential back into the fully passive region. Highly stressed samples required very little incubation time to initiate cracking. It was subsequently observed that the addition of $6 \%$ (by mass) $\mathrm{CuSO}_{4}$ to the $5 \% \mathrm{H}_{2} \mathrm{SO}_{4}$ solution controlled the specimen potential within the susceptible range (at about $0 \mathrm{~V}_{\mathrm{SCE}}$ ) without the use of a potentiostat, and the majority of later experiments was therefore performed in a $5 \% \mathrm{H}_{2} \mathrm{SO}_{4}-6 \% \mathrm{CuSO}_{4}$ solution at a temperature between $50^{\circ} \mathrm{C}$ and $65^{\circ} \mathrm{C}$ to accelerate failure.

The influence of Mode 2 heat-affected zone sensitization was investigated by depositing a transverse weld bead on rectangular plate samples. After welding the samples were subjected to a sensitization treatment in a molten lead bath to simulate the deposition of a second overlapping weld bead at various distances from the fusion line. Heat treatment temperatures between $400^{\circ} \mathrm{C}$ and $750^{\circ} \mathrm{C}$, and times ranging from 15 seconds to 1 hour were used. The welded sections were stressed and immersed in a $5 \% \mathrm{H}_{2} \mathrm{SO}_{4}-6 \% \mathrm{CuSO}_{4}$ solution at $50^{\circ} \mathrm{C}$. Specimens that did not crack were removed from the solution after one week.

Cracking was observed to initiate in the HTHAZ at threshold stress levels of approximately $170 \mathrm{MPa}$ (or about half the yield stress). As shown in Figure 10, four different timetemperature domains were established (for samples stressed up to the yield strength). At low tempering temperatures and times the specimens were unaffected. At higher temperatures and times, the samples failed by IGSCC. At even higher temperatures and times, no cracking occurred and the samples failed by general intergranular corrosion and thinning. This corresponds to the temperature-time domain where grain boundary sensitization could be detected using the oxalic acid etching method. The whole of the martensite phase became anodic with respect to the ferrite, and a specific potential was not required for general corrosion as for SCC. At even higher temperatures and times, desensitization (healing) occurred and the samples were unaffected.

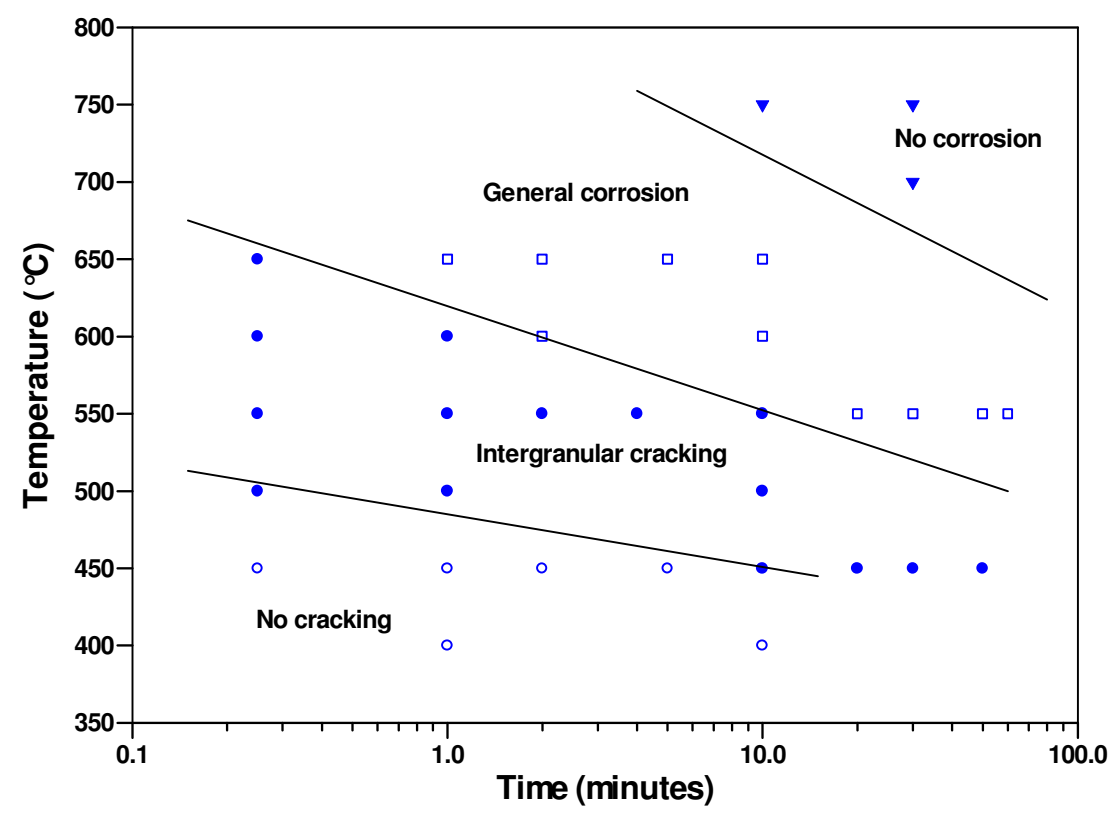

Figure 10 - Sensitization temperatures and times required for stress corrosion cracking in a $5 \% \mathrm{H}_{2} \mathrm{SO}_{4}-6 \% \mathrm{CuSO}_{4}$ solution at $50^{\circ} \mathrm{C}$, measured at an applied stress level of $340 \mathrm{MPa}[20]$. 
The results shown in Figure 10 suggest that susceptibility to SCC is a precursor to general intergranular corrosion. Within the sensitization temperature range, carbide precipitation occurs very early. The initial carbide that forms is, however, not $\mathrm{Cr}$-rich, and it is only at higher temperatures and times that the chromium-rich $\mathrm{M}_{23} \mathrm{C}_{6}$ carbide appears. SCC of sensitized martensite displays all the characteristics of anodic dissolution of the prior austenite grain boundaries, assisted by the application of an external stress. The austenite grain boundaries provide energetically favourable nucleation sites for carbide precipitation, whereas diffusion is rapid within the highly dislocated martensite phase. This promotes susceptibility to SCC at relatively low temperatures. By comparison, the martensite lath boundaries that form at temperatures below about $450^{\circ} \mathrm{C}$ are not as favourable as austenite grain boundaries for the nucleation of $\mathrm{M}_{23} \mathrm{C}_{6}$. Eventual precipitation on the lath boundaries results in general intergranular corrosion of the grain boundary martensite phase.

Williams et al [17] confirmed that a corrosive environment is required for IGSCC, although atmospheric exposure alone can be sufficient to cause IGSCC in highly sensitized heataffected zone regions. More corrosive environments appear to lower the threshold stress values for SCC. Through-thickness propagation of IGSCC has been observed in the sensitized heat-affected zones of 1.4003 steels at applied stress levels of about 40 to $50 \%$ of the parent metal yield stress on exposure to a neutral $\mathrm{pH}$ laboratory salt spray environment (consisting of 5 to $7 \% \mathrm{NaCl}$ vapour at a humidity level of $98 \%$ and a temperature of $35^{\circ} \mathrm{C}$ ) for a period of 96 hours. In the field, IGSCC failures associated with Modes I and 2 sensitization have been observed to occur in welds where the applied stress levels have been estimated to be only about $20 \%$ of the parent metal yield strength. A number of salt spray test specimens failed under laboratory conditions in the absence of any external stress, suggesting that residual tensile stresses can be sufficient to initiate SCC in highly sensitized welded samples. IGSCC occurs after increasingly shorter times as the applied stress level increases relative to the yield strength of the parent material. At any given stress level the rate of progress of IGSCC is influenced by the degree of sensitization in the heat-affected zone.

\subsection{Slow strain-rate testing}

Matthews et al [6] examined the effect of Mode 1 and Mode 2 sensitization on the material's susceptibility to IGSCC by performing a series of slow strain-rate tensile tests on 1.4003 steel in various conditions. The tensile tests were performed at a crosshead speed of $3 \mathrm{~mm}$ per hour in air or in a $5 \% \mathrm{H}_{2} \mathrm{SO}_{4}+6 \% \mathrm{CuSO}_{4}$ solution at a temperature of $65^{\circ} \mathrm{C}$. The results of the slow strain-rate tests are shown in Figure 11.

The curve shown for as-received (hot rolled, annealed and pickled) material tested in air provides a baseline curve for comparison. Results labled "Single weld" refer to samples containing a single butt weld deposited on as-received or heat treated material, whereas those labled "Double weld" refer to as-received plate containing two welds overlapping in such a way as to induce Mode 2 heat-affected zone sensitization. The curves labled "HT" refer to material heat treated above the $A_{1}$ temperature at $850^{\circ} \mathrm{C}$ for 30 minutes in order to simulate incorrectly annealed base material, followed by water quenching to give a ferriticmartensitic microstructure in the parent metal. This material was then welded with a single butt weld to simulate Mode 1 sensitization.

The results shown in Figure 11 indicate that welding on as-received material did not significantly influence the steel's performance in air, with failure occurring within the base metal. In a nonaggressive environment (such as air), the presence of either a single or a double weld therefore appears to have little influence on the metal's performance. A simulated heat treatment above the $A_{1}$ temperature prior to welding changed the material's properties significantly due to the presence of untempered martensite in the base metal, with the material displaying considerably higher strength and reduced ductility. When tested in a corrosive environment, the steel fails rapidly at a much lower stress and strain level than in air. The total strain to failure is less than $4 \%$. Material containing a double weld (i.e. Mode 2 
sensitization), however, displayed similar stress-strain behaviour whether tested in the aggressive solution or in air, although fracture occurred after only about $11 \%$ strain in the test solution. This is nearly half the strain that can be accommodated in air, and significantly higher than the total strain to fracture in material that had been heat treated above the $A_{1}$ temperature.

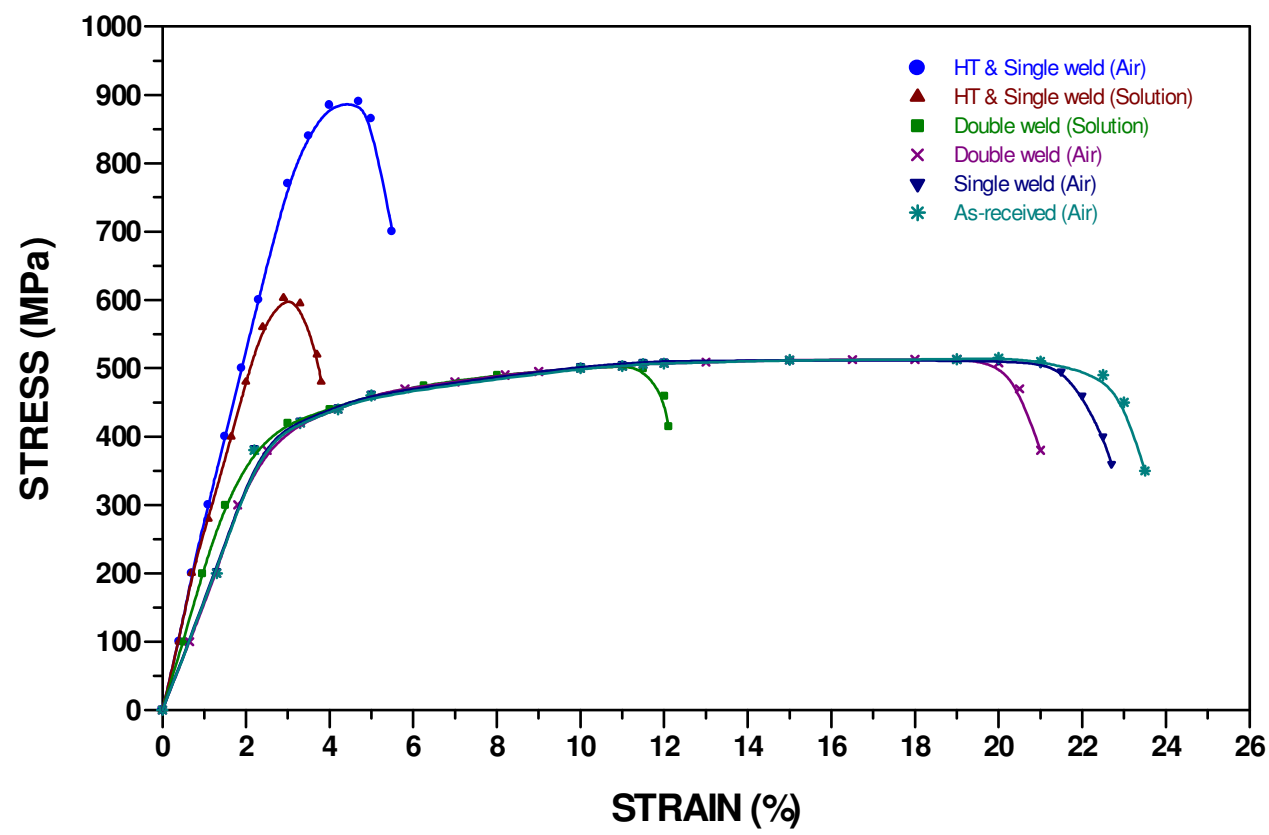

Figure 10 - Slow strain-rate test results for 1.4003 steel in various conditions tested in air or in a $5 \% \mathrm{H}_{2} \mathrm{SO}_{4}-6 \% \mathrm{CuSO}_{4}$ solution at $65^{\circ} \mathrm{C}$ [6].

These results suggest that, even though Mode 1 and Mode 2 sensitization have a similar metallurgical mechanism, incorrectly heat treated material (Mode 1) is normally considerably more susceptible to corrosive attack. This was confirmed by field inspections which revealed heat-affected zone pitting corrosion in incorrectly heat treated material exposed to air (unusual for 1.4003 steels), whereas material with overlapping heat-affected zones in the same mildly corrosive environment displayed no evidence of corrosive attack.

\section{CONCLUSIONS}

Low carbon, 12\% chromium type 1.4003 ferritic stainless steels have been found to be susceptible to heat-affected zone sensitization under very specific conditions. Sensitization may lead to intergranular pitting and stress corrosion cracking within the heat-affected zone on exposure to a corrosive environment. Four distinct modes of sensitization have been identified to date:

- Mode 1: Sensitization of martensite within the heat-affected zone of welds deposited on incorrectly annealed parent metal with a dual-phase ferrite-martensite microstructure.

- Mode 2: Sensitization of martensite when multiple welds are positioned in such a way that the heat-affected zone of the $2^{\text {nd }}$ pass overlaps the heat-affected zone of the $1^{\text {st }}$ pass.

- Mode 3: Sensitization of $\delta$-ferrite within the high temperature heat-affected zone during rapid cooling after welding at very low heat input levels.

- Mode 4: Sensitization of austenite within the high temperature heat-affected zone during very slow cooling after welding at excessively high heat input levels. 
Although the conditions leading to sensitization and intergranular stress corrosion cracking are readily simulated in the laboratory, instances of actual field failures have been rare. Failures can normally be prevented by ensuring that final annealing is always performed below the $A_{1}$ temperature, heat inputs are maintained within the recommended range of about $0.5 \mathrm{~kJ} / \mathrm{mm}$ to $1 \mathrm{~kJ} / \mathrm{mm}$, and weld configurations and joint geometries that produce overlapping heat-affected zones are avoided. Titanium-stabilized grades of 1.4003 are generally not susceptible to Mode 1 , Mode 2 or Mode 4 sensitization, but may be susceptible to Mode 3 sensitization if the austenite potential is low.

\section{REFERENCES}

1. 3CR12 - The Utility Stainless Steel. 1997. Technical Manual published by Columbus Stainless.

2. 3CR12 - Technical Data. 2004. Technical Manual published by Columbus Stainless.

3. Maxwell, D.K., Warrington, J., and Dewar, K. 1993. From niche to commodity, 3CR12 - a tenyear scenario. Corrosion Reviews 11(3-4): pp. 17-32.

4. Grobler, C. 1987. Weldability studies on $12 \%$ and $14 \%$ chromium steels. PhD dissertation. University of Pretoria, South Africa.

5. Meyer, A.M. 2000. Interstitial diffusion from the weld metal into the high temperature heat affected zone in 11 - 12 percent chromium steel welded joints. MEng thesis. University of Pretoria, South Africa.

6. Matthews, L.M., Griesel, B., Longman, P.T., Van Rooyen, G.T., and Prozzi, J.M. 1999. Sensitisation in low-carbon $12 \%$ chromium containing stainless steels. Proceedings of the $14^{\text {th }}$ International Corrosion Congress. Cape Town, South Africa: p. 332.

7. Folkhard, E. 1988. Welding Metallurgy of Stainless Steels. Springer-Verlag, Vienna: p. 11.

8. Greeff, M.L. 2005. The influence of welding parameters on the sensitisation behaviour of 3CR12. MSc thesis. University of Pretoria, South Africa.

9. Bavarian, B., Szklarska-Smialowska, Z., and MacDonald, D.D. 1982. Effect of temperature on the stress corrosion cracking of tempered type 403 martensitic stainless steel in sodium sulfate solution. Corrosion 38(12): pp. 604-608.

10. Nishimura, R. 1992. Stress corrosion cracking of type 430 ferritic stainless steel in chloride and sulfate solutions. Corrosion 48(11): pp. 882-890.

11. Frangini, S. 1994. Sensitivity to stress corrosion cracking of type 405 stainless steel in hightemperature aqueous environments. Corrosion 50(6): pp. 447-456.

12. Číhal, V. 1984. Intergranular Corrosion of Steels and Alloys. Material Science Monographs, 18. Elsevier: pp. $79-83$.

13. Solomon, H.D., and Devine T.M. 1984. Duplex Stainless Steels - A tale of two phases. Proceedings of Duplex Stainless Steels. St. Louis, USA: pp. 693-756.

14. Tuling, A. 2001. EELS study of sensitisation in $12 \%$ chromium steel. Proceedings of the Microscopy Society of Southern Africa 31: p. 26.

15. Tomari, H., Fujiwara, K., Shimogori, K., Fukuzuka, T., and Kanda, M. 1982. Intergranular stress corrosion cracking of $13 \% \mathrm{Cr}$ and $18 \% \mathrm{Cr}$ ferritic steels in high temperature high purity water. Corrosion 38(5): pp. 283-294.

16. Frangini, S., and Mignone, A. 1992. Modified electrochemical potentiokinetic reactivation method for detecting sensitisation in 12 wt.\% chromium ferritic stainless steels. Corrosion 48(9): pp. 715-726.

17. Williams, J.G., and Barbaro, F.J. 2005. Sensitisation and intergranular stress corrosion cracking of the HAZ of welded $12 \% \mathrm{Cr}$ ferritic stainless steels. Australasian Welding Journal $50\left(4^{\text {th }}\right.$ quarter): $34-47$.

18. Greeff, M.L., and Du Toit, M. 2005. Sensitisation of two 11-12\% chromium type EN 1.4003 ferritic stainless steels during continuous cooling after welding. IIW Document IX-2182-05.

19. Kaltenhauser, R.H. 1982. Source book on the Ferritic Stainless Steel. ASM Engineering Bookshelf: pp. 212-218.

20. Van Rooyen, G.T. 2000. The susceptibility of $12 \% \mathrm{Cr}$ steel to SCC after welding. Fracture 2000. Cape Town, South Africa. 